\title{
Insulin and IGFs in renal cancer risk and progression
}

\author{
W Solarek ${ }^{1,2}$, A M Czarnecka', B Escudier ${ }^{3}$, Z F Bielecka ${ }^{1,2}$, F Lian ${ }^{4}$ and C Szczylik ${ }^{1}$ \\ ${ }^{1}$ Laboratory of Molecular Oncology, Department of Oncology, Military Institute of Medicine, \\ Szaserow 128, 04-141 Warsaw, Poland \\ ${ }^{2}$ School of Molecular Medicine, Medical University of Warsaw, Warsaw, Poland \\ ${ }^{3}$ Institut Gustave Roussy, 114 rue Edouard Vaillant, 94805 Villejuif, France \\ ${ }^{4}$ Emory University School of Medicine, Atlanta, Georgia, USA
}

Correspondence should be addressed to A M Czarnecka Email anna.czarnecka@gmail.com

\begin{abstract}
Insulin and IGFs play a significant role in cancer development and progression, including renal cell carcinoma (RCC). RCC is the most frequent type of kidney cancer in adults and the tenth most common malignancy worldwide. Insulin is normally associated with metabolism control, whereas IGFs are defined as proliferation regulators. Today, there is convincing evidence of an association between obesity and the risk of RCC. Indicated risk factors together with type 2 diabetes are irreversibly connected with circulating insulin and IGF levels. The interplay between these molecules, their receptors, and IGF-binding proteins might be crucial for RCC cell biology and RCC progression. Given the potent activity IGF/IGF receptor 1 (IGF1R) inhibitors demonstrate against RCC in basic research, some type of combination therapy may prove to be beneficial clinically in the management of RCC. This review addresses not only molecular but also clinical associations between insulin and IGF1 signaling pathways and both RCC biology and clinical course. Revealing these interactions may improve our understanding of basic molecular oncology processes in RCC and improve treatment strategies.
\end{abstract}

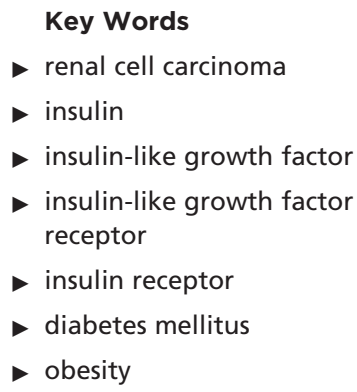

\section{Introduction}

Renal cell carcinoma (RCC), the incidence and mortality of which are rising at a rate of $2-3 \%$ per decade, is the tenth most common malignancy worldwide and the most frequent type of kidney cancer in adults. Approximately 88400 patients are diagnosed with RCC each year in Europe (Gupta et al. 2008, Ljungberg et al. 2011). Although obesity, hypertension, diabetes, and male gender are known risk factors for RCC, its specific etiology is unknown (Murai \& Oya 2004, Larsson \& Wolk 2011). The fact that diabetes results from failure of insulin production by the pancreatic B-cells and insulin resistance in peripheral tissues is well established (Berry \& Helwig 1948). The main mechanism, which is believed to underline the associations between diabetes and RCC, is chronic hyperinsulinemia irreversibly connected with pre-diabetic and diabetic status (Lindblad et al. 1999, Frasca et al. 2008). Recent advances in the molecular basis of RCC have allowed for a better understanding of the genetic disturbances that lead to renal carcinogenesis. Central to the biology of RCC is the loss of function of the von HippelLindau (VHL) tumor suppressor gene, leading to the stabilization of hypoxia-inducible factors and inhibition of insulin-like growth factor receptor 1 (IGF1R) signaling (Datta 2000, Zhang et al. 2013). The interplay between insulin and the IGF system might be relevant to RCC development and progression. In this review, we describe the role of insulin and insulin-like growth factors (IGFs) from both a clinical and a molecular point of view.

Published by Bioscientifica Ltd. 
Monitoring patient diabetic status or diet is an irreversible part of treatment, and a better understanding of its molecular background can improve patient outcome.

\section{The role of insulin and IGFs in physiological conditions}

\section{Insulin and IGFs}

Insulin is a peptide hormone produced by $\beta$ cells in the pancreas and a crucial regulator of carbohydrate and fat metabolism. As insulin is normally linked with metabolism control, IGFs, mainly produced in the liver, were identified as proliferation regulators (Pollak 2008). This classical view, although in general correct regarding its basic premises, has become more complex due to recent findings. It is known that insulin is produced as a preprohormone from the INS gene located in $11 \mathrm{p} 15.5$, then gradually cleaved to form the A chain and B chain peptides, which are covalently linked via two disulfide bonds to form insulin and C-peptide. IGF1 and IGF2 genes are located in 12q23.2 and 11p15.5 respectively. Interestingly, a read-through INS-IGF2 gene exists. Its $5^{\prime}$ region overlaps the INS gene and the $3^{\prime}$ region overlaps gene IGF2. $I G F 2$ is an imprinted gene, expressed only from the paternal allele, so loss of imprinting could account for its frequent overexpression in neoplastic tissues (Kaneda et al. 2007). Both IGF1 and IGF2 genes produce different isoforms because of alternative splicing. In contrast to many other regulatory peptides, insulin and IGFs regulate physiology not only at the whole organism level but also at the cellular level. Rabkin \& Schaefer (2004) showed that IGF1 administered to animals promotes renal growth via the processes of cellular hypertrophy and hyperplasia and, both in the animal model and in humans, induces a rapid increase in renal blood flow and glomerular filtration.

\section{Insulin and IGF receptors and signaling pathways}

Structurally similar, insulin and IGFs act through similar receptors built as a tetrameric complex, characterized by two halves, which consist of an extracellular $\alpha$-chain that is involved in ligand binding and an intracellular $\beta$-chain with functional tyrosine kinase (TK) domain. In adult tissues, insulin receptor (IR) is mainly expressed in adipose tissue and the muscle and liver, while IGF1R is expressed in almost all human tissues. Interestingly, cells expressing both IR and IGF1R may present hybrid receptors (HRs), which consist of an insulin half receptor and an IGF1 half receptor (Soos et al. 1990, Pollak 2008). Such HRs might activate both insulin and IGF signaling systems. Moreover, IR can be expressed in two isoforms: IR-A and IR-B. The first is the fetal splice variant and is obtained by exon 11 skipping (Mosthaf et al. 1990, Sen et al. 2009). Interestingly, it was shown that cancer cells commonly express IR-A isoform in contrast to normal insulin-sensitive tissues in adults, which express IR-B isoform (Belfiore 2007). The IR-A receptor responds more effectively to the activation by IGF2 than IR-B and binds this molecule with the same affinity as IGF1R, which can be crucial in promoting cancer cells growth (Frasca et al. 1999, Kara et al. 2015). IR, IGF1R, and HR bind insulin, IGF1, or IGF2 with different affinities, thus they variously activate TKs, which phosphorylate IR substrate (IRS) proteins as well as several other signaling proteins (DOK4, DOK5, SHC, Gab1, Cbl, APS, SIRP). Because of phosphorylation, IRS interacts with the 885 regulatory subunit of PI3K, which is crucial for the metabolic effects of insulin (Fig. 1).

Downstream of IR and IRS are the Akt and MAPK intracellular networks, which drive a variety of processes including cell growth, cell division, and apoptosis. The Akt activation mediates anti-apoptotic functions of insulin and IGFs through phosphorylation of BAD family proteins and FKHR proteins (Frasca et al. 2008). A comparison of IR and IGF1R showed that phosphorylation of IRS1 protein

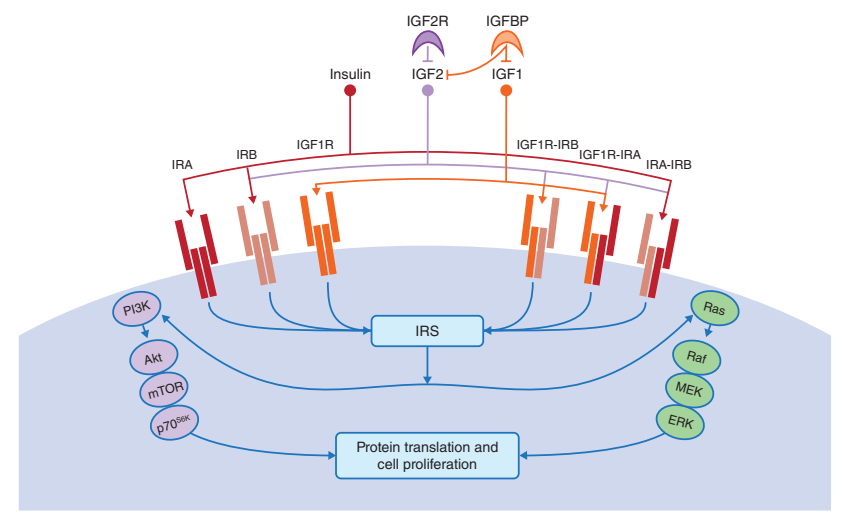

Figure 1

Insulin and insulin-like growth factor (IGF) key elements at the cellular level. The insulin receptor family consists of two insulin receptor isoforms (IRA and IRB) and the type 1 insulin-like growth factor receptor (IGF1R), which can function either as a homo- or heterodimer. Insulin binds primarily to the insulin receptor (IR), but also to the IGF1R with lower affinity. IGF1 and IGF2 bind to IGF1R and IGF1R/IR HRs. Insulin-like growth factor binding proteins (IGFBPs) and type 2 insulin-like growth factor receptor (IGF2R) bind to and prevent IGF1 or IGF2 from activating receptor signaling cascade. IGF1R/IR signaling is mediated intracellulary by insulin receptor substrate (IRS), which leads to the activation of PI3K-AKT or MAPK pathways and finally to protein translation and cell proliferation. A full colour version of this figure is available at http://dx.doi.org/ 10.1530/ERC-15-0135.

Published by Bioscientifica Ltd. 
was ten times more sensitive to insulin than to IGF1, but MAPK stimulation and DNA synthesis were equally activated by both (Mastick et al. 1994). Another analysis revealed slightly different results: insulin and IGF1 were shown to stimulate IRS-1 phosphorylation in similar doseand time-dependent manners; however, IGF1 was more efficient in activating the MAPK pathway and DNA synthesis (Sasaoka et al. 1996). However, there is no evidence that IR-related events cannot be mediated by IGF1R and vice versa. Signaling specificity probably results from the relative efficacy level at which the receptors engage different signaling pathways (Siddle 2012).

Apart from IR and IGF1R, cells can also express the IGF2 receptor (IGF2R) known as a mannose 6-phosphate receptor (M6P-R), which has been defined as a tumor suppressor gene product. IGF2R binds IGF2 but does not transduce a signal. Rather, it targets it to lysosomal degradation and thus sequestrates it away from IGF1R (Leboulleux et al. 2001). In human serum, the majority of IGF1 and IGF2 are bound to one of the IGF binding proteins (IGFBPs), which limit its access to IGF1R. The circulating concentrations of IGF1 $(\sim 20 \mathrm{nmol} / \mathrm{l})$ and IGF2 $(\sim 90 \mathrm{nmol} / \mathrm{l})$ are higher than insulin $(\sim 0.5 \mathrm{nmol} / \mathrm{l})$. Nonetheless, insulin has direct access to its receptor. However, in some situations, overexpression of IGFBPs was correlated with increased IGF action (Pollak 2008). Moreover, IGFBPs were shown to exert their biological functions in an IGF-independent manner (Werner et al. 2008).

\section{The clinical importance of insulin and IGFs in RCC risk and progression}

\section{Obesity and diabetes mellitus influence on RCC development risk}

Currently, there is convincing evidence regarding a positive association between obesity (linked to hyperinsulinemia) and a risk for several cancers: adenocarcinoma of the esophagus and gastric cardia, colorectal cancer, postmenopausal breast cancer, endometrial cancer, and clear cell RCC (O'Mara et al. 1985, Wideroff et al. 1997, Hjartåker et al. 2008, Renehan et al. 2008). Obesity is a major risk factor for type 2 diabetes, the risk of which increases continuously with an increasing BMI (Chow et al. 2000). Even moderate obesity is strongly associated with both type 2 diabetes mellitus (DM) and renal cell cancer (Goodman et al. 1986, Lindblad et al. 1999, Wang et al. 2012). Moreover, in two single-institutional studies, it was shown that, in the group of patients with renal masses treated with surgery, increasing BMI was independently associated with clear-cell histology (Donat et al. 2006, Lowrance et al. 2010). Every $1 \mathrm{~kg} / \mathrm{m}^{2}$ increase in BMI correlated with a $4 \%$ odds increase of having clear-cell variant of RCC (Lowrance et al. 2010). A population-based retrospective cohort study of patients identified in the Swedish Inpatient Register showed 267 occurrences of RCC in diabetic patients compared to an expected number of 182.4. In this analysis, both women and men with a history of diabetes had around a 50\% excess risk independent of other risk factors such as hypertension (Lindblad et al. 1999). Similar results were obtained in the Japan Collaborative Cohort Study for Evaluation of Cancer Risk, which included 46462 males and 64326 females and illustrated that diabetes increases the risk of death from kidney cancer (Washio et al. 2007).

Interestingly, it was reported in several epidemiological studies that insulin resistance status (mainly connected with hyperinsulinemia) is associated with an increased risk of renal cancer (Frasca et al. 2008). In 2011, it was again demonstrated that type 2 diabetes is independently associated with an increased risk of renal cell cancer in women. A follow-up of 118177 women over 32 years documented 16819 cases of type 2 diabetes and 330 cases of RCC. It was shown that obesity, hypertension, and type 2 diabetes significantly increase the risk of RCC. In addition, an increased risk was observed during the early years of diabetes compared to later stages, which may be connected to the natural course of hyperinsulinemia in type 2 diabetes (Joh et al. 2011). The most accurate systematic meta-analysis review confirmed a statistically significant association between DM and an increased risk of kidney cancer (1.42; 95\% CI 1.06-1.91). This association was stronger in women than in men (relative risk (RR) 1.70 vs 1.26 respectively). In this meta-analysis, diabetes was more strongly associated with total and unspecified kidney cancer compared with renal cell cancer (Larsson \& Wolk 2011). Overall, these data suggest a role of chronically elevated insulin levels, which may affect insulin and IGF signaling pathways and thus facilitate cancer development.

Typically, type 2 diabetes occurs after long-term insulin resistance following hyperinsulinemia and then pancreatic B-cell failure. This subsequently leads to hypoinsulinemia (Joh et al. 2011). Recently, other studies revealed the impact of diabetes status on prognosis after nephrectomy in RCC (Lee et al. 2012, Fukushima et al. 2013, Ha et al. 2013, Vavallo et al. 2014). A multiinstitutional analysis of 2597 patients with localized RCC showed that DM was an independent prognostic factor in terms of recurrence-free, cancer-specific, and

Published by Bioscientifica Ltd. 
overall survival (Ha et al. 2013). In contrast, other investigations did not confirm such association and suggested that diabetes does not have any impact on RCC prognosis (Antonelli et al. 2013, Süer et al. 2013). Moreover, another institutional case control study (which enrolled 60 RCC patients and 236 age- and gendermatched healthy controls) revealed an inverse association between RCC risk and insulin levels using an univariate model. Patients in the 2nd and 3rd tertile for insulin levels had approximately a $40 \%$ reduced risk compared with those in the 1st tertile (Spyridopoulos et al. 2012). Nevertheless, the insulin levels were measured after diagnosis. This study also revealed a decreasing trend of insulin levels with increased tumor stage, which suggests that RCC may shift to a less insulin-dependent model in the course of progression. Potentially, high insulin stimulation may lead to altered expression of the IR fetal splice variant $\mathrm{A}$ isoform, which in turn enhances proliferation and promotes carcinogenesis. A significantly increased expression of the A isoform of the IR was observed in RCC tissue samples compared with a normal kidney. It was suggested that IR-A, in response to both insulin and IGF2, may play a role in the upregulation of angiogenesis, cell survival promotion, and cancer progression (Takahashi et al. 2005) (Table 1).

Although the causes of diabetes-related RCC are still unknown, an interconnection between the diabetic kidney and marked hypertrophia has been identified, suggesting its potential role in nephrocarcinogenesis. In addition, the increased expression of IGF1, IGF1R, constituents of MAPK and IR, and alterations in carbohydrate metabolism have been documented in RCC and in diabetic kidneys (Dombrowski et al. 2007). Renal hypertrophy in the mouse model is connected with a persistent accumulation of renal IGF1 and IGFBP1, which could be reversed with insulin therapy. Interestingly, insulin therapy did not correct the hyperglycemia, suggesting an important role of insulin deficiency in mediating such changes in the IGF system (Segev et al. 1997).

Another mechanism, proposed to explain the association between diabetes and kidney tumorigenesis, emphasizes the role of chronic hyperglycemia. It was revealed that, in kidney cortex tissue of RCC patients with diabetes, hyperglycemia leads to the hyperactivation of the Akt/mTOR signaling pathway and a decrease in the OGG1 enzyme (tuberin resulted in a decrease in DNA repair enzyme) as well as the accumulation of oxidative DNA damage. Interestingly, all of these activated proteins were predominantly identified in tubular cells - the cells from which RCC develops. In effect, long-term exposure of tubular cells to hyperglycemia may cause disturbances in DNA repair mechanisms and thus may lead to RCC development (Habib \& Liang 2014).

\section{IGF1 fasting level as a prognostic factor for patients with RCC}

In clinical studies carried out over the last decade, epidemiology focused on another element of the IGF system: IGF1 and its influence on RCC risk and progression. It was shown that serum IGF1 at diagnosis is related to prognosis in RCC; interestingly, prognosis was more favorable in those with higher levels. Moreover, in a multivariate analysis, the serum IGF1 level was an independent prognostic factor in RCC (Rasmuson et al. 2004). It should be emphasized that in the prospective Finnish study of 29133 male smokers aged 50-69 years, IGF1 levels above $113 \mathrm{ng} / \mathrm{ml}$ correlated with a $59 \%$ decrease in kidney cancer risk compared with lower IGF1 levels. The same study did not show any association between the IGF binding protein-3 (IGFBP3) level and the risk of RCC (Major et al. 2010). Considering IGF1

Table 1 Diabetes mellitus and IGF1 correlations with RCC risk and prognosis

Authors
Lindblad et al. (1999)
Washio et al. (2007)
Joh et al. (2011)
Fukushima et al. (2013)
Ha et al. (2013)
Lee et al. (2012)
Rasmuson et al. (2004)
Major et al. (2010)

\begin{tabular}{l}
\hline Factor \\
\hline Diabetes mellitus \\
Diabetes mellitus \\
Diabetes mellitus \\
Diabetes mellitus \\
Diabetes mellitus \\
Diabetes mellitus \\
IGF1 levels above a median \\
IGF1 levels $<113$ ng
\end{tabular}

Correlated with
RCC risk and mortality
RCC mortality
RCC risk
RCC recurrence after
nephrectomy
RFS and OS
OS
More favorable prognosis
Increase in RCC risk

No. of RCC patients
267 of 153852
66 of 110788
330 of 118177
543
2597
950
256
100

Significance
No data
HR 2.22 Insignificant
HR 1.60
$P<0.001$
$P=0.003$
HR $1.82, P=0.01$
HR 2.48, $P<0.001$
$P=0.022$
$P=0.017$
No data

RFS, relapse-free survival; OS, overall survival. 
functioning on the molecular level and its pro-proliferative effects, these results seem to indicate opposite roles of these molecules. On the contrary, it was illustrated that high IGF1 pretreatment levels in patients with established RCC strongly predict an impaired response to interleukin 2 (IL2) therapy, which is consistent with the postulated role of IGF1 and should be reconciled with IGF1's role in modern anti-angiogenic therapies of RCC (Lissoni et al. 1995) (Table 1).

\section{The role of immunohistochemical detection of IR, IGFs, and IGF1R in RCC prognosis}

IGF, IR, and IGF1R levels and RCC correlation has also been studied by pathologists. Microarray and immunoreactivity projects have shown frequent overexpression of IGF1 and IGF1R in RCC, suggesting the existence of an autocrineparacrine loop of tumor cell stimulation. In detailed analyses, the IGF system was shown to be differentially expressed among specific tumor types; clear-cell RCC IGF1 was expressed in $82.1 \%$ of the cases and IGF1R in $29.5 \%$. In this study, it was not related to tumor stage, grade, or prognosis (Schips et al. 2004). In another study, it was shown in a population-based cohort that immunohistochemical detection of IGF1R expression in RCC is associated with the Fuhrman nuclear grade (the grading schema of RCC) (Ahmad et al. 2004) and worse cancerspecific survival (Parker et al. 2002, 2003, 2004). IGF1R expression was demonstrated to be negatively correlated with patient survival based on Kaplan-Meier analysis and to be a prognostic factor in patients with RCC based on Cox regression analysis (Sichani et al. 2010). Only one study correlated IR immunohistochemical detection with RCC prognosis. IR expression was present in 109 of 126 (87.9\%) RCC tissue samples and was significantly related to a lower Fuhrman nuclear grade and better patient prognosis. Interestingly, IR expression was the same for RCC and adjacent normal tissues and was not related to the diabetes status of patients (Lkhagvadorj et al. 2014).

In the latest study by Kosti et al., kidney cortex tissue from patients with diabetes, RCC, RCC with coexisting diabetes, and healthy controls was analyzed using immunostaining as well as microarray analysis to find genetic gain/loss and determine the overlap of enriched pathways. Immunostain data highlighted a significant increase in IR expression in diabetes and RCC + diabetes tissue groups, which was consistent with the microarray screen. The highest IR DNA copy number was found in the RCC+ diabetes group, which suggests that such DNA alteration may be engaged in the early stages of tumor initiation. Also, this genome-wide research reported differences in DNA copy number variations (CNV) between kidney tissue samples derived from patients with RCC + diabetes, diabetes, and RCC. Diabetic patients showed increased CNV, which may suggest that hyperglycemia or hyperinsulinemia is likely to cause genomic alterations, possibly leading to oncogenesis. Patients with RCC and coexisting diabetes had most of the genomic variations.

The Database for Annotation, Visualization and Integrated Discovery (DAVID) screen revealed shared pathway disturbances between diabetes and RCC groups, which comprise changes in transcriptional, nuclear, chromosomal parts, and protein-DNA complexes organization. When comparing the RCC + diabetes and diabetes groups, four Gene Ontology (GO) functions were found overlapping: response to cytokine stimulus, ubiquitindependent protein catabolic processes, ATPase activity, and adenyl nucleotide binding. Interestingly, IR had gains in the DNA copy number in RCC+diabetes and diabetes but not in the RCC group, which suggests IR's potential role in nephrocarcinogenesis in patients with diabetes. Although the impact of presented similarities in gene copy number changes remains unclear, presented data suggest that DNA alterations in IR may play an important role in the early stages of tumorigenesis and have a potential to become predictive biomarkers for RCC development in diabetic patients (Kosti et al. 2015).

All of these results link the IGF system molecular actions with its probable role in carcinogenesis and cancer progression. A study of functional characteristics of the insulin and IGF1 receptors in human RCC revealed that RCC contained three- to fourfold more specific insulinbinding sites and twofold more IGF1-binding sites than adjacent normal kidney tissue. Furthermore, significantly increased receptor autophosphorylation and elevated substrate phosphorylation was found in RCC tissue (Kellerer et al. 1995). These processes could probably facilitate cancer cell proliferation and thus enhanced cancer growth and progression.

\section{IGF binding proteins}

Another member of the IGF system, IGFBPs, which limit IGF1 access to IGF1R, may play a significant role in RCC development and progression. Although studies confirming this hypothesis are limited, it was supported by a combination of cDNA microarrays, western blot, and immunohistochemistry analysis that IGFBP3 is a potent marker for clear-cell RCC. Higher IGFBP3 expression was also associated with a higher Fuhrman grade, which

Published by Bioscientifica Ltd 
indicates a more aggressive cancer phenotype (Chuang et al. 2008). Moreover, it was claimed that IGFBP3 gene variants are associated with RCC. Using a large and independent cohort of RCC patients, Dong et al. (2009) found that common genetic variants of IGFBP3 are associated with renal cancer risk. The nucleotide $202 \mathrm{AA}$ genotype was significantly higher in patients with RCC than in controls (Safarinejad 2011). IGFBP expression was also proved to be differentially regulated according to the histologic subtype of RCC; clear-cell RCCs were characterized by significant increases in the mRNA expression of IGFBP3 and IGFBP6 (Hintz et al. 1991, Cheung et al. 2005, Takahashi et al. 2005). Expression of another IGFBP protein, IGFBP4, was shown to be significantly lower in primary RCC cells and higher in metastatic RCC when compared to normal human kidney tissues. These results raise the question about the potential role of IGFBPs in affecting IGFs signal transmission and thus their impact on cancer progression, all of which needs further investigation.

\section{Molecular impact of insulin and IGFs on RCC cells}

Over the last 20 years, it was proven that receptor TKs are vital to the formation and progression of human cancers, sarcomas, and lymphomas (Frasca et al. 2008, Hjartåker et al. 2008). In particular IGF1R, a TK receptor for IGF1 and IGF2, has been well documented in cell culture models as well as in animal studies to play a role in malignant transformation, progression, and protection from apoptosis and in metastasis (Dombrowski et al. 2007, Major et al . 2010, Joh et al. 2011). At the same time, the insulin and its TK receptor have been shown both in vitro and in vivo to play an important role in cancer cell biology.

\section{Insulin role in RCC development - in vivo animal model studies}

It was proposed also that insulin level disturbances might lead to cancer through insulin's effect on its cognate receptor and the IGF system. For instance, in the rat diabetes model, nephrocarcinogenesis resulted from sustained hyperglycemia. This further led to an adaptive metabolic response, altered growth factor signaling, and subsequent transformation of the tubular epithelial cells (Dombrowski et al. 2007). This frequently used diabetes model is based on the application of streptozotocin (STZ), which enters the $\beta$-cells via a glucose transporter (GLUT2) and causes DNA alkylation, leading to irreversible damage of the islets of Langerhans. The consequence of such dysfunction is a long-term insulin deficiency and chronic high fasting glucose level (Wei et al. 2003, Vinerean et al. 2011). One study demonstrated an association between experimentally induced DM in rats and the development of RCC. An additional argument is that the development of RCC in autoimmune-diabetic rats occurs without administration of any exogenous agent. Moreover, it has been shown that the main nephrocarcinogenic effect of STZ depends on the induction of diabetes, because the RCC incidence was higher in hyperglycemic rats compared with insulin-treated normoglycemic animals (Dombrowski et al. 2007). This study showed that hyperglycemia might affect RCC development rather than hyperinsulinemia. Earlier analysis had revealed higher expression of IGF1R and increased IGF1 and IGF2 binding in the diabetic kidney of STZ-induced rats, which may suggest the existence of an autocrine or paracrine system in the STZ-treated kidney (Werner et al. 1990). However, in a study conducted by Lauder et al. (1981), STZ-induced diabetic rats developed liver or renal tumors regardless of whether blood glucose was controlled or not. Another group concluded that an STZ-induced diabetic rat model is not suitable for long-term studies because of progressive renal tumorigenesis, which is caused by STZ rather than diabetes. This group's research revealed that diabetic rats developed RCC regardless of the exogenous insulin treatment or peritoneal implantation of porcine islets in macrobeads (Vinerean et al. 2011). Their results demonstrated an interconnection between hyperinsulinemia, hyperglycemia and RCC rather difficult. In summary, there is no clear answer regarding the role of insulin and IR in RCC development and progression.

\section{The role of IGF1 and IGFBP3 in RCC growth and progression - in vitro and in vivo approach}

Compared to insulin and IR, IGFs and their receptors are much better understood. In animal models and in humans, IGF1 has been shown to increase normal kidney growth, glomerular filtration rate, and renal function (Hirschberg \& Adler 1998). Definitely, IGF1 and its receptor are present in the kidney, and in this way, they both may be engaged in the development of RCC. In the in vitro project involving three primary cell cultures of RCC, Cheung et al. (2004) have shown that these RCC cells express IGFI and IGFBP3 and are responsive to exogenous IGF1 stimulation. Moreover, in cells derived from metastatic RCC, autocrine IGF1, and IGFBP3 actions, respectively, stimulate and inhibit growth. IGFBP3 acts in the

Published by Bioscientifica Ltd. 
kidney probably through the sequestration of IGF1 from its receptor. It was also proven in this report that IGF1 stimulates DNA synthesis in normal renal cells as well as RCC cells. Furthermore, IGF1 immuno-neutralization, similar to IGFBP3, suppresses lung metastasis-derived RCC cells and normal proximal tubular cells growth but not primary tumor-derived RCC cells growth. Overexpression of IGFBP3 inhibited the growth of lung metastasisderived RCC cells, but not normal renal cells or primary tumor RCC cells. It was estimated that the expression of IGF1 together with its receptor, IGF1R, provides evidence for the existence of an autocrine-paracrine loop of tumor cell stimulation in RCC. All of these molecules may differentially affect the growth of cells derived from various tissues on different levels of cancer development and progression (Cheung et al. 2004).

Another analysis of IGFs system confirmed that IGF1 has its growth-promoting effects regulated by IGFBP3. Rosendahl \& Forsberg (2004) monitored functional effects of various concentrations of IGF1, transforming growth factor $\beta$ (TGF- $\beta$ ), and IGFBP3 in the primary tumor cell line Caki-2 and metastatic cell line SK-RC-52. They proved that human RCC tissue and two clear-cell RCC cell lines, Caki-2 and SK-RC-52, express IGF1R and IGFBP3. Both cell lines responded to IGF1 and IGF2 through proliferation. Moreover, researchers revealed that competing, non-signaling IGF1R mouse antibody causes stronger inhibition of IGF1induced proliferation in the low IGF1R expression SK-RC52 cells than in IGF1R high Caki-2 cells. They also demonstrated that IGF1, through activation of Smad2 protein phosphorylation and its nuclear translocation, enhances TGF- $\beta$ signaling, which in turn promotes IGFBP3 production. Such interconnection between IGFBP3 expression and IGF1 stimulation may function as a selfregulating system, a disruption that can be connected with cancer development. Depending on which line it affects, IGFBP3 has a different impact on cell proliferation: it stimulates the growth of the primary tumor, inhibiting metastasis at the same time (Rosendahl \& Forsberg 2006). This raises the question of when do pleiotropic cytokines, such as TGF- $\beta$, switch their role during cancer development from tumor suppressor to tumor promoter. To find the answer, the same study group constructed the in vivo model, based on constant infusion of recombinant human IGF1 to severe combined immune-deficient mice bearing early or more established tumors formed from Caki-2 human RCC cell line. They showed that early (day 7 after tumor inoculation) IGF1 administration significantly stimulated the RCC growth in vivo. During establishment or progression, which corresponded to late IGF1 administration (day 21 after tumor inoculation), RCC tumors appeared to become desensitized to such stimulation. This effect was not connected with any change in IGF1R expression but was linked to altered IGF1 sensitivity. Therefore, systemic IGF1 delivery during the early establishment of RCC tumors significantly increased local IGFBP3, phosphorylated nuclear Smad2, and tumor angiogenesis in contrast to the later stage. Those were linked to a markedly enhanced tumor growth and a more aggressive phenotype. The same experiment protocol used with metastatic RCC cell line SK-RC-52 showed that IGF1 intervention did not enhance in vivo tumor growth, regardless of administration time (Rosendahl et al. 2008). These data suggest that IGF1 may influence RCC development in its early stages, although in the course of progression this tumor appears to become desensitized to systemic IGF1 effects. Such discrepancy may occur as an effect of intratumor heterogeneity and epigenetic differences among cancer cell populations (Gerlinger et al. 2012). It was shown in the epigenetic reactivation screen of renal cancer that IGFBP1 and IGFBP3 genes, normally unmethylated, had a methylated promoter in tumor cells (Ibanez de Caceres et al. 2006). Disturbed promoter methylation is a common mechanism for the inactivation of tumor suppressor genes in cancer cells. This points to IGFBP1 and IGFBP3 as genes in which abnormal expression may affect RCC risk and progression.

Another intriguing research study was conducted by Jungwirth et al. who investigated the effects of growth hormone-releasing hormone antagonist (GH-RH) and somatostatin analog on the proliferation of the human RCC cell line Caki-1 (isolated from skin metastasis) in vitro and in vivo. They showed that both GH-RH antagonist and somatostatin analog inhibit the growth of the tumor formed after transplantation of Caki-1. Moreover, GH directly regulates the IGF1 production in the liver and other organs, so in this experiment, both GH-RH antagonist and somatostatin analog possibly constrained tumor growth in the mechanism involving suppression of IGFs. Furthermore, mice treated with the GH-RH antagonist or somatostatin analog exhibited significantly lower IGF1 serum levels than controls, and these in vitro studies revealed that the addition of IGF1 or IGF2, but not GH, to the culture medium resulted in proliferation stimulation of the cell line Caki-1. What is more, untreated animals had high tissue concentrations of IGF1 and IGF2, which decreased after GH-RH treatment. The observations from the in vitro studies suggest an existence of IGF autocrine or paracrine loop stimulating tumor cell proliferation, an

Published by Bioscientifica Ltd 
inhibition that may be used in future treatment strategies (Jungwirth et al. 1997, 1998).

\section{IGF1R signaling pathway disturbances in RCC}

VHL protein Among multiple molecules involved in RCC carcinogenesis, a group of tumor suppressors was identified as well. They are linked to transcriptional suppression of the IGF1R gene and include p53/p63/p73 family, breast cancer gene-1, VHL, and Wilms' tumor-1 protein (Werner et al. 1996, Datta 2000, Werner 2011). In particular, VHL, the expression of which is altered in most of sporadic RCC, was shown to inhibit IGF1 cell signaling. Datta et al. studied IGF1 cell signaling in 786-O RCC cell line and revealed that IGF1R antibodies inhibit cell proliferation. They also presented data showing that WT VHL, which normally is inactivated in RCC, inhibits the IGF1R-mediated signaling pathway through the blockade of IGF1R and protein kinase C delta association. Thus, in RCC, the IGF1R signaling pathway may be chronically activated, which can promote cancer growth and progression. Consistently, they proved that the invasive activity of RCC in the cell culture model is mediated through IGF1R signaling and can be efficiently blocked by VHL protein (Datta 2000). Another research group also confirmed that IGF1R protein levels are higher in RCC cells lacking functional VHL and do not correlate with hypoxia conditions, which makes them hypoxiainducible factor (HIF)-protein independent (Yuen et al. 2007). Their findings support the hypothesis that phosphorylated VHL negatively regulates IGF1R expression and thus link it to the interaction with Sp1 protein at the transcriptional level. This kind of regulation is analogous to the regulation of VEGF and PDGF expression, although both are also hypoxia-inducible genes. What is more, clinical significance of such observation was also assessed by measuring IGF1R levels in tissue samples of RCC and non-malignant kidneys. An analysis of 21 such paired specimens revealed significantly higher levels of IGF1R mRNA in the RCC tumors compared with the benign kidney (Yuen et al. 2007). IGF1R upregulation may be therefore one of the hypoxia-independent effects of VHL loss on renal tumorigenesis (Fig. 2).

Receptor for activated C kinase 1 Another report by $\mathrm{He}$ et al. showed that the receptor for activated $\mathrm{C}$ kinase 1 (RACK1), which has a significant role to play in shuttling, anchoring, and stabilizing proteins around the cell, is a VHL-interacting protein and a crucial regulator of the IGF1-induced cellular invasiveness (He et al. 2010,

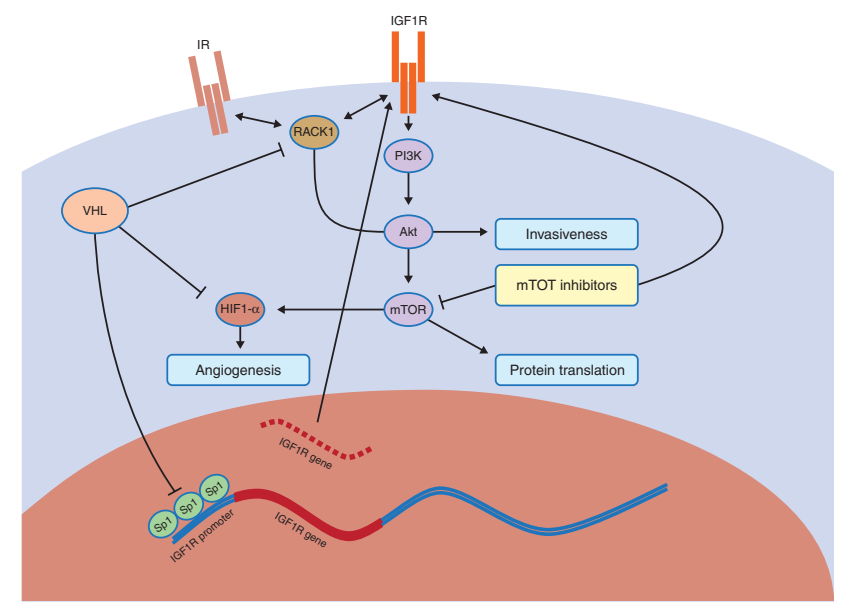

Figure 2

Insulin and insulin-like growth factor 1 receptors (IR and IGF1R) intracellular signaling pathways and the impact of mTOR inhibitor on IGF1R dependent Akt activation. Activated von Hippel-Lindau protein (VHL) inhibits type 1 insulin-like growth factor receptor (IGF1R) cell signaling through the interaction with Sp1 transcription factor and both IR and IGF1R interaction with the receptor for activated C kinase 1 (RACK1) and causes hypoxia-inducible factor 1 (HIF1) degradation. VHL-deficient renal cell carcinoma (RCC) cells exhibit increased IR/IGF1R-RACK1 interaction, elevated IGF1R expression level, Akt activation, and MMP-2 expression, which are associated with increased protein translation, RCC cell proliferation, and invasiveness, as well as enhanced angiogenesis. mTOR inhibitors used in RCC therapy affects cell proliferation and survival as well as angiogenesis but simultaneously activates the Akt-signaling pathway through an IGF1R-dependent mechanism. A full colour version of this figure is available at http://dx.doi.org/10.1530/ERC-15-0135.

Adams et al. 2011). Moreover, RACK1 also interacts with the closely related IR (Adams et al. 2011). This study identified that, on IGF1 treatment, VHL-deficient RCC cells exhibit increased IGF1R-RACK1 interaction, elevated IGF1R, Akt activation, and MMP-2 expression. Taken together, these results may suggest that VHL-RACK1 interaction negatively regulates the activation of the IGF1R/Akt/MMP-2 signals and suppresses IGF1-dependent invasiveness in RCC cells (He et al. 2010). It shows another molecular mechanism in which VHL loss affects RCC development and progression (Fig. 2).

\section{IGF1R inhibition as a therapeutic approach in} RCC Linking information about signaling pathways with cancer treatment, the other scientific group revealed that antitumor agents, mTOR inhibitors, inadvertently activate the Akt-signaling pathway through an IGF1Rdependent mechanism (Wan et al. 2006). One study showed that the blockade of IGF1 binding to IGF1R and downregulation of this receptor are equally effective in inhibiting RCC cell line growth and combining with mTOR inhibitor - temsirolimus works in synergy. Synergism of

Published by Bioscientifica Ltd. 
IGF1R inhibitors with mTOR inhibitors was observed in an in vivo model of a pediatric tumor in which such combination led to complete tumor regression. Recently, many IGF/IGF1R inhibitors have entered clinical trials but several of them failed to show clinical benefit (Chen \& Sharon 2013). The results suggest a possible new approach for treating RCC by linking mTOR and IGF1R inhibition, which needs further investigation in animal models and subsequently future clinical trials (Cardillo et al. 2013).

\section{Insulin-like growth factor 2}

Much less is known about the role of IGF2 in these processes. The IGF2 gene is imprinted and transcribed only from paternal allele. Loss of this imprinting (LOI) was implicated in the pathogenesis of many malignancies (Brouwer-Visser \& Huang 2015), as well as RCC cases, but two known analyses showed an inconsistent impact of LOI on IGF2 mRNA expression. However, in both analyses it was presented that LOI in IGF2 gene was not involved in later stages of RCC development but may occur in some early tumors, which raises the question about the role of IGF2 in RCC carcinogenesis (Nonomura et al. 1997, Oda et al. 1998). It was shown in the in vivo model that in hypoxic conditions IGF2 stimulates the homing of endothelial progenitor cells and thus promotes angiogenesis (Maeng et al. 2009). Further research is therefore needed.

\section{Conclusions}

Although phenomenal progress in understanding renal cell cancer basics and therapy is observed, the results of RCC treatment are still unsatisfactory and too many patients do not survive. Unfortunately, many patients are presented with advanced RCC, which requires systematic treatment. In the near future available therapies will be combined with new molecular targeted agents. Significant progress will require advanced analysis of multiple aspects of RCC biology for the identification and optimization of reliable RCC biomarkers. Both insulin and IGFs are thought to affect cancer development and progression, but the exact molecular mechanism behind this phenomenon has not been yet revealed. Moreover, data about insulin impact on cancer development and progression are limited. In a controversial animal model study with STZ, it was shown that insulin may decrease the probability of renal tumor development through the reduction of hyperglycemia. Looking at clinical data, there is no doubt that overweight, obesity, and type $2 \mathrm{DM}$ are connected with the increased risk of RCC occurrence. As all of these pathological conditions are related to disturbances in insulin and probably IGFs signaling systems, it was suggested that they all might influence RCC tumorigenic processes. In a few clinical studies, it was revealed that diabetes is an independent risk and prognostic factor for RCC.

Currently, more experiments are being conducted to investigate the role of IGFs. IGF1 is actually known to stimulate the growth of RCC cells in in vitro as well as in vivo conditions; this may be the result of inactivated VHL, characteristic for most RCCs. Inactive VHL is unable to inhibit IGF1R-mediated signaling pathway, which when activated promotes RCC invasiveness and progression through the interaction with RACK1 and subsequent Akt and MMP-2 activation. Akt pathway, sensitive to IGF1 stimulation in RCC cells, is additionally activated during mTOR inhibitors usage. As these inhibitors are one of RCC therapy options, simultaneous IGF1R inhibition can be a new future RCC treatment approach. Although IGF1 was shown to promote cell proliferation in experimental models, IGF1 serum level turned out to be a positive prognostic factor among patients with RCC. On the contrary to clinical data and what is consistent with the experimental model, high IGF1R expression in immunostained RCC samples was associated with poorer cancer-specific survival. Another part of the IGF system, IGFBP was also shown to correlate with an increased aggressiveness of cancer, despite its inhibitory role in the IGF system. Unlike IGF1R, the IR expression was significantly related to a lower Fuhrman nuclear grade, which is associated with a better prognosis for the patient. To date, insulin and IGFs can neither be used as biomarkers for RCC screening nor for controlling RCC patient therapy. However, future clinical trials with IGF1R inhibitors may prove to be beneficial for cancer patients.

\section{Declaration of interest}

The authors declare that there is no conflict of interest that could be perceived as prejudicing the impartiality of this review.

\section{Funding}

A M Czarnecka and W Solarek have been supported by the National Science Centre projects No. UMO-2012/05/D/NZ5/01844.

\section{References}

Adams DR, Ron D \& Kiely PA 2011 RACK1, a multifaceted scaffolding protein: structure and function. Cell Communication and Signaling 922. (doi:10.1186/1478-811X-9-22)

Published by Bioscientifica Ltd. (c) 2015 Society for Endocrinology Printed in Great Britain 
Ahmad N, Keehn CA \& Coppola D 2004 The expression of insulin-like growth factor-I receptor correlates with Fuhrman grading of renal cell carcinomas. Human Pathology 35 1132-1136. (doi:10.1016/j.humpath. 2004.05.012)

Antonelli A, Arrighi N, Corti S, Zanotelli T, Cozzoli A, Cosciani Cunico S \& Simeone C 2013 Pre-existing type-2 diabetes is not an adverse prognostic factor in patients with renal cell carcinoma: a single-center retrospective study. Urologic Oncology 31 1310-1315. (doi:10.1016/j. urolonc.2011.12.013)

Belfiore A 2007 The role of insulin receptor isoforms and hybrid insulin/IGF-I receptors in human cancer. Current Pharmaceutical Design 13 671-686. (doi:10.2174/138161207780249173)

Berry MG \& Helwig FC 1948 Marked insulin resistance in diabetes mellitus. American Journal of Medicine 4 923-926. (doi:10.1016/00029343(48)90490-2)

Brouwer-Visser J \& Huang GS 2015 IGF2 signaling and regulation in cancer. Cytokine \& Growth Factor Reviews 26 371-377. (doi:10.1016/j.cytogfr. 2015.01.002)

Cardillo TM, Trisal P, Arrojo R, Goldenberg DM \& Chang C-H 2013 Targeting both IGF-1R and mTOR synergistically inhibits growth of renal cell carcinoma in vitro. BMC Cancer 13 170. (doi:10.1186/ 1471-2407-13-170)

Chen HX \& Sharon E 2013 IGF-1R as an anti-cancer target - trials and tribulations. Chinese Journal of Cancer 32 242-252. (doi:10.5732/ cjc.012.10263)

Cheung CW, Vesey DA, Nicol DL \& Johnson DW 2004 The roles of IGF-I and IGFBP-3 in the regulation of proximal tubule, and renal cell carcinoma cell proliferation. Kidney International 65 1272-1279. (doi:10.1111/j.1523-1755.2004.00535.x)

Cheung C, Vesey D, Cotterill A, Douglas M, Gobe G, Nicol D \& Johnson D 2005 Altered messenger RNA and protein expressions for insulin-like growth factor family members in clear cell and papillary renal cell carcinomas. International Journal of Urology 12 17-28. (doi:10.1111/ j.1442-2042.2004.00993.x)

Chow W-H, Gridley G, Fraumeni JF Jr \& Järvholm B 2000 Obesity, hypertension, and the risk of kidney cancer in men. New England Journal of Medicine 343 1305-1311. (doi:10.1056/ NEJM200011023431804)

Chuang S-T, Patton KT, Schafernak KT, Papavero V, Lin F, Baxter RC, Teh BT \& Yang XJ 2008 Over expression of insulin-like growth factor binding protein 3 in clear cell renal cell carcinoma. Journal of Urology 179 445-449. (doi:10.1016/j.juro.2007.09.106)

Datta K 2000 Inhibition of insulin-like growth factor-I-mediated cell signaling by the von Hippel-Lindau gene product in renal cancer. Journal of Biological Chemistry 275 20700-20706. (doi:10.1074/jbc. M909970199)

Dombrowski F, Klotz L, Bannasch P \& Evert M 2007 Renal carcinogenesis in models of diabetes in rats - metabolic changes are closely related to neoplastic development. Diabetologia 50 2580-2590. (doi:10.1007/ s00125-007-0838-2)

Donat SM, Salzhauer EW, Mitra N, Yanke BV, Snyder ME \& Russo P 2006 Impact of body mass index on survival of patients with surgically treated renal cell carcinoma. Journal of Urology 175 46-52. (doi:10.1016/ S0022-5347(05)00054-6)

Dong LM, Brennan P, Karami S, Hung RJ, Menashe I, Berndt SI, Yeager M, Chanock S, Zaridze D, Matveev V et al. 2009 An analysis of growth, differentiation and apoptosis genes with risk of renal cancer. PLOS ONE 4 e4895. (doi:10.1371/journal.pone.0004895)

Frasca F, Pandini G, Scalia P, Sciacca L, Mineo R, Costantino A, Goldfine ID, Belfiore A \& Vigneri R 1999 Insulin receptor isoform A, a newly recognized, high-affinity insulin-like growth factor II receptor in fetal and cancer cells. Molecular and Cellular Biology 19 3278-3288.

Frasca F, Pandini G, Sciacca L, Pezzino V, Squatrito S, Belfiore A \& Vigneri R 2008 The role of insulin receptors and IGF-I receptors in cancer and other diseases. Archives of Physiology and Biochemistry 114 23-37. (doi:10.1080/13813450801969715)
Fukushima H, Masuda H, Yokoyama M, Tatokoro M, Yoshida S, Ishioka J, Matsuoka Y, Numao N, Koga F, Saito K et al. 2013 Diabetes mellitus with obesity is a predictor of recurrence in patients with non-metastatic renal cell carcinoma. Japanese Journal of Clinical Oncology 43 740-746. (doi:10.1093/jico/hyt070)

Gerlinger M, Rowan AJ, Horswell S, Larkin J, Endesfelder D, Gronroos E, Martinez P, Matthews N, Stewart A, Tarpey P et al. 2012 Intratumor heterogeneity and branched evolution revealed by multiregion sequencing. New England Journal of Medicine 366 883-892. (doi:10.1056/NEJMoa1113205)

Goodman MT, Morgenstern H \& Wynder EL 1986 A case-control study of factors affecting the development of renal cell cancer. American Journal of Epidemiology 124 926-941.

Gupta K, Miller JD, Li JZ, Russell MW \& Charbonneau C 2008 Epidemiologic and socioeconomic burden of metastatic renal cell carcinoma (mRCC): a literature review. Cancer Treatment Reviews 34 193-205. (doi:10.1016/j.ctrv.2007.12.001)

Ha Y-S, Kim WT, Yun S-J, Lee S-C, Kim W-J, Park YH, Kang SH, Hong S-H, Byun S-S \& Kim Y-J 2013 Multi-institutional analysis of localized renal cell carcinoma that demonstrates the impact of diabetic status on prognosis after nephrectomy. Annals of Surgical Oncology 20 3662-3668. (doi:10.1245/s10434-013-3147-7)

Habib SL \& Liang S 2014 Hyperactivation of Akt/mTOR and deficiency in tuberin increased the oxidative DNA damage in kidney cancer patients with diabetes. Oncotarget 5 2542-2550.

He X, Wang J, Messing EM \& Wu G 2010 Regulation of receptor for activated $\mathrm{C}$ kinase 1 protein by the von Hippel-Lindau tumor suppressor in IGF-I-induced renal carcinoma cell invasiveness. Oncogene 30 535-547. (doi:10.1038/onc.2010.427)

Hintz RL, Bock S, Thorsson AV, Bovens J, Powell DR, Jakse G \& Petrides PE 1991 Expression of the insulin like growth factor-binding protein 3 (IGFBP-3) gene is increased in human renal carcinomas. Journal of Urology 146 1160-1163.

Hirschberg R \& Adler S 1998 Insulin-like growth factor system and the kidney: physiology, pathophysiology, and therapeutic implications. American Journal of Kidney Diseases 31 901-919. (doi:10.1053/ajkd.1998. v31.pm9631833)

Hjartåker A, Langseth H \& Weiderpass E 2008 Obesity and diabetes epidemics: cancer repercussions. Advances in Experimental Medicine and Biology 630 72-93.

Ibanez de Caceres I, Dulaimi E, Hoffman AM, Al-Saleem T, Uzzo RG \& Cairns P 2006 Identification of novel target genes by an epigenetic reactivation screen of renal cancer. Cancer Research 66 5021-5028. (doi:10.1158/0008-5472.CAN-05-3365)

Joh H-K, Willett WC \& Cho E 2011 Type 2 diabetes and the risk of renal cell cancer in women. Diabetes Care 34 1552-1556. (doi:10.2337/ dc11-0132)

Jungwirth A, Schally AV, Pinski J, Groot K, Armatis P \& Halmos G 1997 Growth hormone-releasing hormone antagonist MZ-4-71 inhibits in vivo proliferation of Caki-I renal adenocarcinoma. PNAS 94 5810-5813. (doi:10.1073/pnas.94.11.5810)

Jungwirth A, Schally AV, Halmos G, Groot K, Szepeshazi K, Pinski J \& Armatis P 1998 Inhibition of the growth of Caki-I human renal adenocarcinoma in vivo by luteinizing hormone-releasing hormone antagonist Cetrorelix, somatostatin analog RC-160, and bombesin antagonist RC-3940-II. Cancer 82 909-917. (doi:10.1002/(SICI)10970142(19980301)82:5 < 909::AID-CNCR16> 3.0.CO;2-4)

Kaneda A, Wang CJ, Cheong R, Timp W, Onyango P, Wen B, IacobuzioDonahue CA, Ohlsson R, Andraos R, Pearson MA et al. 2007 Enhanced sensitivity to IGF-II signaling links loss of imprinting of IGF2 to increased cell proliferation and tumor risk. PNAS 104 20926-20931. (doi:10.1073/pnas.0710359105)

Kara I, Poggi M, Bonardo B, Govers R, Landrier J-F, Tian S, Leibiger I, Day R, Creemers JW \& Peiretti F 2015 The paired basic amino acid-cleaving enzyme 4 (PACE4) is involved in the maturation of insulin receptor isoform B: an opportunity to reduce the specific insulin 
receptor-dependent effects of insulin-like growth factor 2 (IGF2). Journal of Biological Chemistry 290 2812-2821. (doi:10.1074/jbc.M114. 592543)

Kellerer M, von Eye Corleta H, Mühlhöfer A, Capp E, Mosthaf L, Bock S, Petrides PE \& Häring HU 1995 Insulin- and insulin-like growth-factor-I receptor tyrosine-kinase activities in human renal carcinoma. International Journal of Cancer. Journal International du Cancer $\mathbf{6 2}$ 501-507. (doi:10.1002/ijc.2910620502)

Kosti A, Chen H-IH, Mohan S, Liang S, Chen Y \& Habib SL 2015 Microarray profile of human kidney from diabetes, renal cell carcinoma and renal cell carcinoma with diabetes. Genes \& Cancer 662.

Larsson SC \& Wolk A 2011 Diabetes mellitus and incidence of kidney cancer: a meta-analysis of cohort studies. Diabetologia 54 1013-1018. (doi:10.1007/s00125-011-2051-6)

Lauder I, Abascal J, Cartwright RA, Farndon JR \& Johnston ID 1981 Liver tumours following streptozotocin administration in rats and the effects of pancreatic islet cell transplantation. Carcinogenesis 2 799-803. (doi:10.1093/carcin/2.8.799)

Leboulleux S, Gaston V, Boulle N, Le Bouc Y \& Gicquel C 2001 Loss of heterozygosity at the mannose 6-phosphate/insulin-like growth factor 2 receptor locus: a frequent but late event in adrenocortical tumorigenesis. European Journal of Endocrinology/European Federation of Endocrine Societies 144 163-168. (doi:10.1530/eje.0.1440163)

Lee S, Hong SK, Kwak C, Kim HH \& Lee SE 2012 Prognostic significance of diabetes mellitus in localized renal cell carcinoma. Japanese Journal of Clinical Oncology 42 318-324. (doi:10.1093/jjco/hys018)

Lindblad P, Chow WH, Chan J, Bergström A, Wolk A, Gridley G, McLaughlin JK, Nyren O \& Adami HO 1999 The role of diabetes mellitus in the aetiology of renal cell cancer. Diabetologia 42 107-112. (doi:10.1007/s001250051122)

Lissoni P, Barni S, Ardizzoia A, Frigerio F, Paolorossi F, Cazzaniga M, Tancini G, Rocco F \& Aapro M 1995 Clinical efficacy of cancer subcutaneous immunotherapy with interleukin-2 in relation to the pretreatment levels of tumor growth factor insulin-like growth factor-1. Tumori 81 261-264.

Ljungberg B, Campbell SC, Cho HY, Jacqmin D, Lee JE, Weikert S \& Kiemeney LA 2011 The epidemiology of renal cell carcinoma. European Urology 60 615-621. (doi:10.1016/j.eururo.2011.06.049)

Lkhagvadorj S, Oh SS, Lee MR, Jung JH, Chung HC, Cha SK \& Eom M 2014 Insulin receptor expression in clear cell renal cell carcinoma and its relation to prognosis. Yonsei Medical Journal 55 861-870. (doi:10.3349/ ymj.2014.55.4.861)

Lowrance WT, Thompson RH, Yee DS, Kaag M, Donat SM \& Russo P 2010 Obesity is associated with a higher risk of clear-cell renal cell carcinoma than with other histologies. BJU International 105 16-20. (doi:10.1111/ j.1464-410X.2009.08706.x)

Maeng Y-S, Choi H-J, Kwon J-Y, Park Y-W, Choi K-S, Min J-K, Kim Y-H, Suh P-G, Kang K-S, Won M-H et al. 2009 Endothelial progenitor cell homing: prominent role of the IGF2-IGF2R-PLC $\beta 2$ axis. Blood $\mathbf{1 1 3}$ 233-243. (doi:10.1182/blood-2008-06-162891)

Major JM, Pollak MN, Snyder K, Virtamo J \& Albanes D 2010 Insulin-like growth factors and risk of kidney cancer in men. British Journal of Cancer 103 132-135. (doi:10.1038/sj.bjc.6605722)

Mastick CC, Kato H, Roberts CT Jr, LeRoith D \& Saltiel AR 1994 Insulin and insulin-like growth factor-I receptors similarly stimulate deoxyribonucleic acid synthesis despite differences in cellular protein tyrosine phosphorylation. Endocrinology 135 214-222.

Mosthaf L, Grako K, Dull TJ, Coussens L, Ullrich A \& McClain DA 1990 Functionally distinct insulin receptors generated by tissue-specific alternative splicing. ЕМBO Journal 9 2409-2413.

Murai M \& Oya M 2004 Renal cell carcinoma: etiology, incidence and epidemiology. Current Opinion in Urology 14 229-233. (doi:10.1097/01. mou.0000135078.04721.f5)

Nonomura N, Nishimura K, Miki T, Kanno N, Kojima Y, Yokoyama M \& Okuyama A 1997 Loss of imprinting of the insulin-like growth factor II gene in renal cell carcinoma. Cancer Research 57 2575-2577.
O'Mara BA, Byers T \& Schoenfeld E 1985 Diabetes mellitus and cancer risk: a multisite case-control study. Journal of Chronic Diseases 38 435-441. (doi:10.1016/0021-9681(85)90139-0)

Oda H, Kume H, Shimizu Y, Inoue T \& Ishikawa T 1998 Loss of imprinting of IGF2 in renal-cell carcinomas. International Journal of Cancer. Journal International du Cancer 75 343-346. (doi:10.1002/(SICI)10970215(19980130)75:3<343::AID-IJC3 > 3.0.CO;2-2)

Parker AS, Cheville JC, Janney CA \& Cerhan JR 2002 High expression levels of insulin-like growth factor-I receptor predict poor survival among women with clear-cell renal cell carcinomas. Human Pathology 33 801-805. (doi:10.1053/hupa.2002.126186)

Parker A, Cheville JC, Lohse C, Cerhan JR \& Blute ML 2003 Expression of insulin-like growth factor I receptor and survival in patients with clear cell renal cell carcinoma. Journal of Urology 170 420-424. (doi:10.1097/ 01.ju.0000071474.70103.92)

Parker AS, Cheville JC, Blute ML, Igel T, Lohse CM \& Cerhan JR 2004 Pathologic T1 clear cell renal cell carcinoma: insulin-like growth factor-I receptor expression and disease-specific survival. Cancer 100 2577-2582. (doi:10.1002/cncr.20322)

Pollak M 2008 Insulin and insulin-like growth factor signalling in neoplasia. Nature Reviews. Cancer 8 915-928. (doi:10.1038/nrc2536)

Rabkin R \& Schaefer F 2004 New concepts: growth hormone, insulin-like growth factor-I and the kidney. Growth Hormone \& IGF Research $\mathbf{1 4}$ 270-276. (doi:10.1016/j.ghir.2004.02.001)

Rasmuson T, Grankvist K, Jacobsen J, Olsson T \& Ljungberg B 2004 Serum insulin-like growth factor- 1 is an independent predictor of prognosis in patients with renal cell carcinoma. Acta Oncologica 43 744-748. (doi:10.1080/02841860410017260)

Renehan AG, Tyson M, Egger M, Heller RF \& Zwahlen M 2008 Body-mass index and incidence of cancer: a systematic review and meta-analysis of prospective observational studies. Lancet 371 569-578. (doi:10.1016/ S0140-6736(08)60269-X)

Rosendahl A \& Forsberg G 2004 Influence of IGF-IR stimulation or blockade on proliferation of human renal cell carcinoma cell lines. International Journal of Oncology 251327.

Rosendahl AH \& Forsberg G 2006 IGF-I and IGFBP-3 augment transforming growth factor- $\beta$ actions in human renal carcinoma cells. Kidney International 70 1584-1590. (doi:10.1038/sj.ki.5001805)

Rosendahl AH, Holly JM, Celander M \& Forsberg G 2008 Systemic IGF-I administration stimulates the in vivo growth of early, but not advanced, renal cell carcinoma. International Journal of Cancer. Journal International du Cancer 123 1286-1291. (doi:10.1002/ijc.23642)

Safarinejad MR 2011 Insulin-like growth factor binding protein-3 (IGFBP-3) gene variants are associated with renal cell carcinoma. BJU International 108 762-770. (doi:10.1111/j.1464-410X.2010.09809.x)

Sasaoka T, Ishiki M, Sawa T, Ishihara H, Takata Y, Imamura T, Usui I, Olefsky JM \& Kobayashi M 1996 Comparison of the insulin and insulinlike growth factor 1 mitogenic intracellular signaling pathways. Endocrinology 137 4427-4434.

Schips L, Zigeuner R, Ratschek M, Rehak P, Rüschoff J \& Langner C 2004 Analysis of insulin-like growth factors and insulin-like growth factor I receptor expression in renal cell carcinoma. American Journal of Clinical Pathology 122 931-937. (doi:10.1309/G7PYORE 7T86HHQYV)

Segev Y, Landau D, Marbach M, Shehadeh N, Flyvbjerg A \& Phillip M 1997 Renal hypertrophy in hyperglycemic non-obese diabetic mice is associated with persistent renal accumulation of insulin-like growth factor I. Journal of the American Society of Nephrology 8 436-444.

Sen S, Talukdar I \& Webster NJ 2009 SRp20 and CUG-BP1 modulate insulin receptor exon 11 alternative splicing. Molecular and Cellular Biology 29 871-880. (doi:10.1128/MCB.01709-08)

Sichani MM, Yazdi FS, Moghaddam NA, Chehrei A, Kabiri M, Naeimi A \& Taheri D 2010 Prognostic value of insulin-like growth factor-I receptor expression in renal cell carcinoma. Saudi Journal of Kidney Diseases and Transplantation 21 69-74.

Published by Bioscientifica Ltd 
Siddle K 2012 Molecular basis of signaling specificity of insulin and IGF receptors: neglected corners and recent advances. Frontiers in Endocrinology 3 34. (doi:10.3389/fendo.2012.00034)

Soos MA, Whittaker J, Lammers R, Ullrich A \& Siddle K 1990 Receptors for insulin and insulin-like growth factor-I can form hybrid dimers. Characterisation of hybrid receptors in transfected cells. Biochemical Journal 270 383-390.

Spyridopoulos TN, Dessypris N, Antoniadis AG, Gialamas S, Antonopoulos CN, Katsifoti K, Adami H-O, Chrousos GP, Petridou ET \& Obesity and Cancer Oncology Group 2012 Insulin resistance and risk of renal cell cancer: a case-control study. Hormones 11 308-315. (doi:10.14310/horm.2002.1359)

Süer E, Öztürk E, Gülpınar Ö, Kayış A \& Baltacı S 2013 Effect of type 2 diabetes mellitus on prognosis of nonmetastatic renal cell cancer. Korean Journal of Urology $\mathbf{5 4} 499$.

Takahashi M, Papavero V, Yuhas J, Kort E, Kanayama H-O, Kagawa S, Baxter RC, Yang XJ, Gray SG \& Teh BT 2005 Altered expression of members of the IGF-axis in clear cell renal cell carcinoma. International Journal of Oncology 26 923-931.

Vavallo A, Simone S, Lucarelli G, Rutigliano M, Galleggiante V, Grandaliano G, Gesualdo L, Campagna M, Cariello M, Ranieri E et al. 2014 Pre-existing type 2 diabetes mellitus is an independent risk factor for mortality and progression in patients with renal cell carcinoma. Medicine 93 e183. (doi:10.1097/MD.0000000000000183)

Vinerean HV, Gazda LS, Hall RD \& Smith BH 2011 Streptozotocin is responsible for the induction and progression of renal tumorigenesis in diabetic WistarFurth rats treated with insulin or transplanted with agarose encapsulated porcine islets. Islets 3 196-203. (doi:10.4161/isl.3.4.16129)

Wan X, Harkavy B, Shen N, Grohar P \& Helman LJ 2006 Rapamycin induces feedback activation of Akt signaling through an IGF-1R-dependent mechanism. Oncogene 26 1932-1940. (doi:10.1038/sj.onc.1209990)

Wang G, Hou J, Ma L, Xie J, Yin J, Xu D, Chang W, Tan X, Su T, Zhang H et al. 2012 Risk factor for clear cell renal cell carcinoma in Chinese population: a case-control study. Cancer Epidemiology 36 177-182. (doi:10.1016/j.canep.2011.09.006)

Washio M, Mori M, Khan M, Sakauchi F, Watanabe Y, Ozasa K, Hayashi K, Miki T, Nakao M, Mikami K et al. 2007 Diabetes mellitus and kidney cancer risk: the results of Japan Collaborative Cohort Study for Evaluation of Cancer Risk (JACC Study): diabetes mellitus and kidney cancer. International Journal of Urology 14 393-397. (doi:10.1111/j.14422042.2007.01744.x)

Wei M, Ong L, Smith MT, Ross FB, Schmid K, Hoey AJ, Burstow D \& Brown L 2003 The streptozotocin-diabetic rat as a model of the chronic complications of human diabetes. Heart, Lung \& Circulation 12 44-50. (doi:10.1046/j.1444-2892.2003.00160.x)

Werner H 2011 Tumor suppressors govern insulin-like growth factor signaling pathways: implications in metabolism and cancer. Oncogene 31 2703-2714. (doi:10.1038/onc.2011.447)

Werner H, Shen-Orr Z, Stannard B, Burguera B, Roberts CT \& LeRoith D 1990 Experimental diabetes increases insulinlike growth factor I and II receptor concentration and gene expression in kidney. Diabetes 39 1490-1497. (doi:10.2337/diab.39.12.1490)

Werner H, Karnieli E, Rauscher FJ \& LeRoith D 1996 Wild-type and mutant p53 differentially regulate transcription of the insulin-like growth factor I receptor gene. PNAS 93 8318-8323. (doi:10.1073/pnas.93. 16.8318)

Werner H, Weinstein D \& Bentov I 2008 Similarities and differences between insulin and IGF-I: structures, receptors, and signalling pathways. Archives of Physiology and Biochemistry 114 17-22. (doi:10.1080/13813450801900694)

Wideroff L, Gridley G, Mellemkjaer L, Chow WH, Linet M, Keehn S, Borch-Johnsen K \& Olsen JH 1997 Cancer incidence in a populationbased cohort of patients hospitalized with diabetes mellitus in Denmark. Journal of the National Cancer Institute 89 1360-1365. (doi:10.1093/jnci/89.18.1360)

Yuen JS, Cockman ME, Sullivan M, Protheroe A, Turner GD, Roberts IS, Pugh CW, Werner H \& Macaulay VM 2007 The VHL tumor suppressor inhibits expression of the IGF1R and its loss induces IGF1R upregulation in human clear cell renal carcinoma. Oncogene $\mathbf{2 6}$ 6499-6508. (doi:10.1038/sj.onc.1210474)

Zhang T, Niu X, Liao L, Cho E-A \& Yang H 2013 The contributions of HIF-target genes to tumor growth in RCC. PLoS ONE 8 e80544. (doi:10.1371/journal.pone.0080544)

Received in final form 14 July 2015 Accepted 28 July 2015
(C) 2015 Society for Endocrinology Printed in Great Britain 